\title{
Comparison of the HU-DBI index between areas of health sciences and other areas of the University of Cuenca, 2016
}

\begin{abstract}
The University is the place where the students learn and develop skills that will allow them to pursue an occupation, and at the same time improve their attitudes, health skills, that allow them to have healthy living habits and lifestyle. Dental health is an essential part of health and represents an important element for the quality of life. In this sense it is intended to evaluate the attitudes and behaviors of dental health using the approved index Hiroshima University Dental Behavior Inventory (HU-DBI) among the different areas of knowledge of the University of Cuenca. This study was a survey with Sociodemographic variables and 20 dichotomous questions of the HUDBI, which was applied after signing the informed consent forms in all the training areas of the University of Cuenca. The response rate was $56 \% \mathrm{~N}=7790$ students, with an average age of 21,15 years, $\mathrm{DS} \pm 2,42$ variance of 5,89 , the male-female ratio is $1: 1,07$. The majority of students are of the urban origin with $82,8 \%$ and the vast majority are single $(7125$ students $=91,4 \%)$. The average of the HU-DBI index is 6,06 with a $\mathrm{DS} \pm 1,81$ and a variance of 3,27 . There is a better index of the students of health science compared with the students of other areas. Comparing them with the dental students and the others of the health sciences, dental students who had no clinical contact with patients didn't have any difference from those of the other health sciences, but the students who have had the clinical contact with patients have a statistically significant difference with the other students of health sciences.
\end{abstract}

Keywords: attitudes, behavior, oral health, students, dental, inventory
Volume 9 Issue 3 - 2018

\author{
Fabricio Lafebre Carrasco, ' Julieta del \\ Carmen Reinoso Carrasco, ${ }^{2}$ Clara Yamilet \\ Serrano Delgado, ${ }^{3}$ Diego Cobos Carrera, ${ }^{4}$ \\ Aldo Mateo Torrachi Carrasco ${ }^{5}$ \\ 'Department of Periodontology and Oral Medicine, Master of \\ Health Research, University of Cuenca, Ecuador \\ ${ }^{2}$ Department of Biochemistry, Master of Toxicology, University \\ of Cuenca, Ecuador \\ ${ }^{3}$ Department of Biology and Genetics, Master of Adolescent \\ Integral Health, University of Cuenca, Ecuador \\ ${ }^{4}$ Department of Epidemiology, Master of Health Research, \\ University of Cuenca, Ecuador \\ ${ }^{5}$ Professor, University of Azuay, Ecuador
}

Correspondence: Fabrice Lafebre Carrasco, Department of Periodontology and Oral Medicine, Master of Health Research, University of Cuenca, Ecuador,

Email fabricio.lafebre@ucuenca.edu.ec

Received: April 23, 2018 | Published: June 20, 2018

\section{Introduction}

The University of Cuenca is a setting that allows its students to develop their potential and abilities through the application of scientific knowledge for responsible and competitive professional practice. In this way it contributes to the welfare and progress of Ecuadorian society. The University of Cuenca should be the space where abilities, knowledge and attitudes for personal and professional practice are developed, allowing individuals to reach maximum potential with regard to activity in their work and their lives. To reach this goal, promotion and prevention programs in health must be implemented in all areas of knowledge of the University of Cuenca ${ }^{1}$ education is one of the factors that determines health; therefore, one expects that the better education is, the better health care will be. ${ }^{2,3}$ Oral health is an essential component of general health. Among chronic pathologies, caries is the most prevalent at the world level, and among the oral pathologies, caries and periodontal disease are considered world public health problems. ${ }^{3}$ This study compared attitudes and behaviors of oral health among different areas of knowledge of the University of Cuenca: health sciences, economic sciences, social sciences and technical sciences. The index of the Hiroshima University Dental Behavior Inventory (HU-DBI), was used to determine if differences exist among the areas. The HU-DBI is a proven and reliable index, translated to Spanish by Jaramillo and colleagues, which is composed of 20 dichotomous questions with a maximum value of $12 .^{2}$ In the literature, differences are reported by gender, ${ }^{4}$ although this is a controversial topic,,$^{5-7}$ and only one study is found that compares areas of knowledge. It analyzes the HU-DBI index among students of odontology and engineering, where differences are found both in attitudes as well as behaviors. ${ }^{8}$ The University of Cuenca study makes comparisons among different areas of knowledge. The object of this study was to determine the level of attitudes and behaviors about oral health of students of the different areas of knowledge of the University of Cuenca during the period March-July of 2016.

\section{Methodology}

A survey-type study was done among a universe composed of 7,790 students of the University of Cuenca, which included students registered in the areas of health sciences (Nursing, Early Stimulation in Health, Phonoaudiology, Medical Imaging, Clinical Laboratory, Medicine and Surgery, Nutrition and Diet, Odontology and Physical Therapy); the area of economic sciences (Business Administration, Accounting and Auditing, Economics, Business Engineering, Marketing and Sociology); the area of social sciences (Law, Culinary Arts, Hotel Management, Family Counseling and Tourism) and the area of technical sciences (Architecture, Agronomical Engineering, Systems Engineering, Engineering in Electronics and Communication, Veterinary Medicine and Zootechnics). Altogether the percentage of response in the aforementioned areas was $56 \%$. The data bases of the pre-degree thesis in the odontology major were used in which the HU-DBI test was applied in the aforementioned areas, ${ }^{9-12}$ plus the data base in odontology compiled by the authors. The variables analyzed were the following: age, sex, current academic year, origin, 
marital status, attitudinal and behavioral level regarding oral health (HU-DBI). This index is composed of twenty dichotomous questions, agree/disagree, which assesses attitudes and behaviors. The maximum attitudinal and behavioral level is 12 and the minimum is 0 . The value was considered according to the resulting number from the test for each of the individuals, and the mean was calculated for each of the three areas. Regarding the questions, if the response was considered to be agree, one point was assigned. In other words, correct questions of agreement (yes) are the following: 4, 9, 11, 12, 16 and 19. Questions of disagreement that are answered negatively (no) are also assigned one point and are the following: 2, 6, 8, 10, 14 and $15 .{ }^{13}$ The data bases compiled in the aforementioned theses were merged, ${ }^{9-12}$ and cleaned up. The SPSS V. 22 Statistics was then used in the analysis of the data to produce the corresponding tables and graphics. The statistical analysis included calculation of summary measures, considering the nature of the variables. In the bivariate analysis, the level of attitudes and practices was related with the areas of science considered, in accordance with the Hiroshima University Dental Behavior Inventory (HU-DBI) questionnaire.

\section{Results}

The distribution of the socio-demographic variables is seen in Table 1. The size of the population polled in the science areas was 7,790 students, with an average age of 21.15 years, with a SD of \pm 2.42 and a variance of 5.89; the ratio man - woman is 1:1.07. The majority of the students, $82.8 \%$, are of urban origin and the great majorities, 7,125 students $(91.4 \%)$, are unmarried. The average of the HU-DBI index is 8.06 with a $\mathrm{SD} \pm 1.81$ and a variance of 3.27 .

Table 1

\begin{tabular}{|c|c|c|c|}
\hline Variable & & $n=7790$ & $\%$ \\
\hline \multicolumn{4}{|l|}{ Sex } \\
\hline & Male & 3760 & $48,26 \%$ \\
\hline & Female & 4030 & $51,73 \%$ \\
\hline \multicolumn{4}{|l|}{ Origin } \\
\hline & Urban & 6447 & $82,80 \%$ \\
\hline & Rural & 1343 & $17,20 \%$ \\
\hline \multirow{2}{*}{\multicolumn{4}{|c|}{$\begin{array}{l}\text { Marital } \\
\text { Status }\end{array}$}} \\
\hline & & & \\
\hline & Single & 7121 & $91,41 \%$ \\
\hline & Married & 484 & $6,21 \%$ \\
\hline & Divorced & 43 & $0,55 \%$ \\
\hline & Widowed & 44 & $0,56 \%$ \\
\hline & Common-law marriage & 98 & $\mathrm{I}, 25 \%$ \\
\hline \multicolumn{4}{|l|}{ Fields } \\
\hline & Health Sciences & 1867 & $23,96 \%$ \\
\hline & Economic Sciences & 1882 & $24,15 \%$ \\
\hline & Social Sciences & 1334 & $17,12 \%$ \\
\hline & Technical Sciences & 2707 & $34,74 \%$ \\
\hline \multicolumn{4}{|l|}{ Age } \\
\hline & $16-21$ & 4886 & $62,72 \%$ \\
\hline Variable & & $n=7790$ & $\%$ \\
\hline & $22-26$ & 2502 & $32,11 \%$ \\
\hline
\end{tabular}

$\begin{array}{lll}27-31 & 207 & 2,65 \% \\ 32-35 & 9 & 0,11 \% \\ 36-46 & 7 & 0,08 \%\end{array}$

AVERAGE

HU -DBI

\section{Global \\ Source: Data Form \\ Elaboration: the authors}

6,06

Distribution of student socio-demographic variables in the areas of health sciences, economic sciences, social sciences, and technical sciences of the University of Cuenca 2016. In Figure 1 one can see that there is an obvious difference in the means, which corresponds to a better HU-DBI index in health sciences with respect to other areas of knowledge Figure 2. Distribution of HU-DBI according to gender in the areas of knowledge of the University of Cuenca Figure 3. Distribution of HU-DBI according to origin in the areas of knowledge of the University of Cuenca Table 2. In this study, it has been shown that a difference exists in the HU-DBI index between the areas of health sciences and other areas of knowledge of the University of Cuenca. The ANOVA test yielded 1,113.467 with a statistical significance of $\mathrm{p}=0.000$.

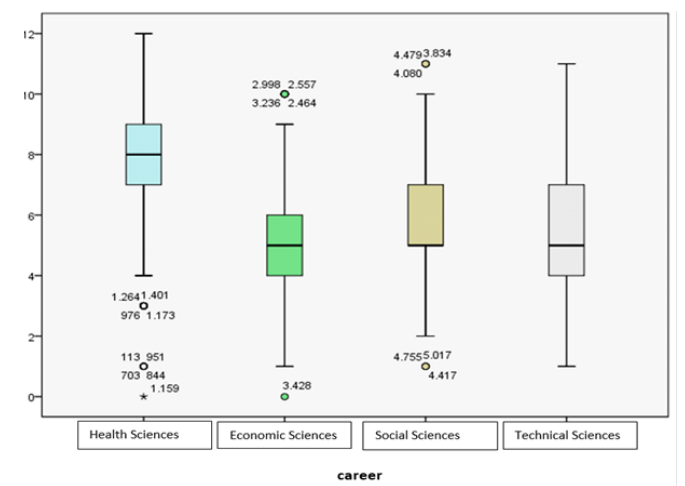

Figure I Distribution of the HU-DBI index by areas of knowledge of the University of Cuenca. 2016.

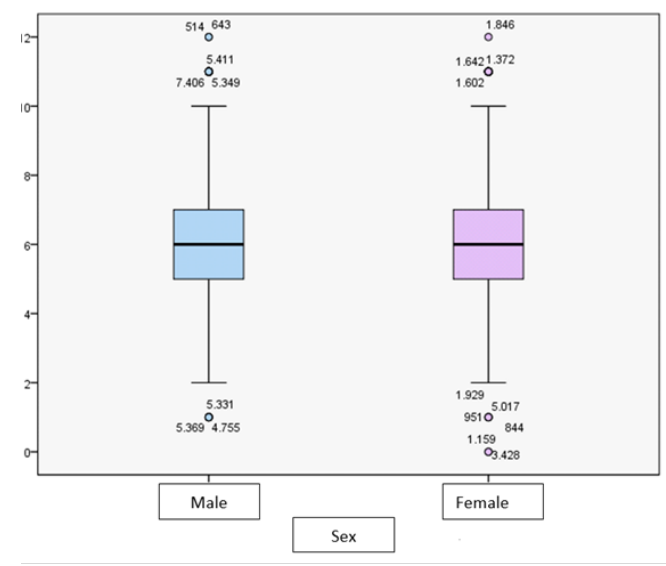

Figure 2 Shows that there is no difference in the HU-DBI index with respect to gender. 


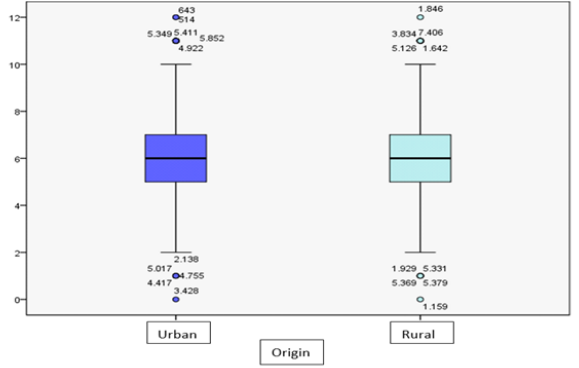

Figure 3 Shows that there is no difference in the HU-DBI index with respect to origin.

Table 2 Distribution of Chi Square according to age

\begin{tabular}{llll}
\hline Chi square & & & \\
\hline & Value & gl & Sig. asintotic (2 sides) \\
\hline Pearson Chi-square & $51,220^{\mathrm{a}}$ & 48 & 349 \\
likelihood ratio & 50,139 & 48 & 389 \\
Asociación lineal por & 20 & $\mathrm{I}$ & 888 \\
lineal & 7790 & & \\
$\mathrm{~N}$ valid cases & & &
\end{tabular}

\section{Logistic regression}

This table, which compares beginning students in the University of Cuenca with those in the last year, shows they improve their HUDBI index. Consequently, it demonstrates that education has effects on improvements in health. The estimation has finalized at iteration number 7 because estimations of the parameters have changed in less than.001.

\section{Summary of the model}

In the regression, non-significant results were merged; in other words, health was contrasted with the rest. It must be mentioned what the most relevant items are. For example, questions 6 and 2 are the most discriminating with $\mathrm{OR}$ of 27 and 11, respectively. Questions such as 11,12,14,16, 18 etc., do not discriminate groups. In other words, in principle they do not serve to assess oral health (or something similar.)

\section{Discussion}

\section{Differences exist between ages determined by Chi Squared 51.220, gl48 and significance 0,349 .}

This study has a response rate of $56 \%$ in the entire university, which is a considerable number of responses, considering the difficulty of surveying the entire population in addition to being a voluntary test. There is no statistically significant difference in the proportion of men - women between the population and the sample. This is the first study that compares all the fields of study grouped in the different areas of health, economics, social studies and technical studies. In place of origin there is a very large predominance between urban and rural; $82.8 \%$ is urban, which signifies that persons from the countryside do not have access to the university in the same proportion as those in the city. This is a young population with the majority unmarried $(91,41 \%)$, which also indicates it is the end of adolescence and the beginning of productive life. The majority of the students $(95 \%)$ are between 16 and 26 years of age. The areas are distributed in a proportional way, taking into consideration the structure of majors in the University of Cuenca, namely that the sample reflects the proportion of the universe. Consequently, it is a representative sample of the universe $(56 \%)$ and is also a model of what occurs in the country's southern region, as it is a regional university and could represent what occurs in the population age structure. The global HU-DBI index of the university was 6,06. This index is one of two valid instruments to measure attitudes and behaviors in oral health reported in the literature. Its original version, utilized by Kawamura in 1988, is composed of 20 dichotomous questions, eight of which are considered dummies, and which are not considered for the final test assessment. ${ }^{14}$ Various studies have been carried out with the object of determining and comparing attitudes and behavior in oral health of odontology students of different countries and considering the cultures and learning contexts. In this way an evaluation between Japan and Australia was made by Kawamura in 1997; Japan and Finland in 2000, and Japan and France among others. This study is the first that takes into consideration all the areas of knowledge of the University of Cuenca and compares attitudes and behaviors among the different areas, which is only reported by Jaramillo and colleagues, but does not report an index as such, rather differences in the responses..$^{15}$ Therefore, our study provides a parameter of comparison among different areas of the study. The conclusions of different investigations suggest the existence of two large groups of individuals, one of western culture and the other of oriental culture, with the first having more positive characteristics regarding attitude and conduct of self-care in oral health. ${ }^{16}$ Komabayashi y Kawamura have not found differences between first year odontology students and other students in non-related majors. ${ }^{17}$ Assuming that knowledge of oral diseases is scarce, the students are not motivated regarding dental maintenance, and there is no concern for aesthetics or dental pain.

Upon comparison of odontology and dental hygiene students and dental technicians in Jordan in the last two years, one observes that the HU-DBI values increase with age and level of education, in other words attitudes and behaviors in oral health were more positive. Odontology and dental hygiene students were better, and technicians were the worst. It was also found that females were more concerned about appearance than males; consequently they had more positive attitudes than men and higher HU-DBI values. All the odontology students needed to improve their behaviors in hygiene and oral health to be models for their patients. The global HU-DBI index found in our study is 6.06, which apparently does not differ from students in the United States., which is 6.30, as reported by Kawamura and associates in 2002, and apparently would differ from the Koreans, which were 5.88 in the same study. ${ }^{18}$ The global index in our study results from the fact that the health sciences area registers $7.72(\mathrm{SD} \pm 1.58)$, the economic sciences area registers $5.50(\mathrm{SD} \pm 1.47)$, the social sciences area registers $5.56(\mathrm{SD} \pm 1.57)$, and the technical sciences area registers 5.54 ( $\mathrm{SD} \pm 1.56)$. On comparing the health sciences areas alone with respect to the Kawamura study, our students would have a better index of knowledge and oral health attitudes. With respect to the difference between students in the School of Medical Sciences and the School of Odontology, a prior investigation about to be published found that no significant difference existed upon comparison of the HU-DBI index between odontology students at the pre-clinic level and the other health sciences majors. Another study by Lafebre and colleagues found, however, that a difference existed between pre-clinic and clinic 
students of the School of Odontology, a change explained by students' contact with patients, itself fostering preventive activities in patients. ${ }^{19}$ In the area of health sciences of the University of Cuenca, the index is higher than other areas because these students have subjects that cover health promotion and prevention, knowledge that changes their attitudes and conducts, which is reflected in the HU-DBI index on comparison with the other areas.

It is important to consider that on comparing the HU-DBI index in all areas of the University of Cuenca between students that enter and those who complete their studies, there is significant improvement in their attitudes and conducts in oral health. This relates to what was suggested by Rong and associates 2006, who carried out a longitudinal study between students of medicine and dental health from the first to the fifth year, finding no HU-DBI differences among first-year students, but differences among final-year students. ${ }^{20} \mathrm{We}$ could conclude that odontology students improved their index due to contact with patients and their curricular formation, and students in the area of health also improved with the knowledge gained from their curricular formation. Other areas of knowledge of the University of Cuenca improved from entrance to graduation in general terms. It was found that from the first to the fourth year of study in the entire university, the average of the index remained at 6 , but in the fifth year (graduation year) there was an increase in the HU-DBI average to 7, which indicates that education does favor an improvement in health. According to the UNESCO, "Education is a determining factor in health. It is well known that those who are most predisposed to have bad health are not only the poorest, but those who have a lower level of education." ${ }^{21}$ The explanation of the researchers is that the knowledge of hygienists in oral health, psychology and community health is fundamental to influencing oral health knowledge and students' self-care. Rong and associates 2006 carried out a longitudinal study between students of medicine and dental health from the first to the fifth years and did not find differences in the values of the HU-DBI index in the first year, but did find differences in the final years. (20) Rong 2006 finds the difference between students of odontology and medicine to be $6 \pm 1.64$ and $5.9 \pm 1.79$, respectively, but not of statistical significance..$^{22}$

In this study it was found that no significant difference exists when comparing the HU-DBI index between odontology students at the pre-clinic level with students of the other health science majors. This does not signify a controversy exists with the former study carried out in the School of Odontology of the University of Cuenca, in which the study compared students of the pre-clinic and clinic levels. There a significant difference existed between the two groups, which was explained by the contact of the latter with patients, which itself reinforced the attitudes and behaviors of oral health, reflected in the greater HU-DBI index. ${ }^{19}$ In four pre-graduation research studies, it was determined that, in general, students in the health majors have better indexes than in the other majors. ${ }^{9-12}$ Educating about health is an important task performed by a health professional, in other words, teaching and stimulating patients to acquire favorable attitudes and behaviors, ${ }^{23}$ an activity which also generates beneficial results for them. ${ }^{24}$ This should be a competence achieved by the end of health education. ${ }^{25,26}$ According to the previous study, students who enter the odontology major have an average index of 8 , and those who complete the major have an index of 9.49 , explained by the clinic contact. ${ }^{19}$ In this study we find that the average index of the other health sciences majors remains unchanged. This should serve to consider an intervention in public health.

\section{Conclusion}

Education strengthens oral health attitudes and behaviors, according to the criteria of the HU-DBI. And it improves even more in health science students and much more in students of the dental career.

\section{Acknowledgements}

None.

\section{Conflict of interest}

The author declares that there is no conflict of interest.

\section{References}

1. Promoviendo universidades saludables 2010. Ministerio de Salud. 2017:4-41.

2. Petersen PE. Improvement of oral health in Africa in the $21^{\text {st }}$ centurythe role of the WHO Global Oral Health Programme. Afr J Oral Health. 2004;1(1):2-16.

3. Organización Panamericana de la Salud. La OMS publica un nuevo informe sobre el problema mundial de las enfermedades bucodentales. WHO. 2004

4. AJ Sharda, S Shetty. A comparative study of oral health knowledge, attitude and behaviour of first and final year dental students of Udaipur city, Rajasthan. India Int J Dent Hygiene. 2008;6(4):347-353.

5. Baseer MA, Rahman G, Al Kawaey Z, et al. Evaluation of oral health behavior of female dental hygiene students and interns of Saudi Arabia by using Hiroshima University Dental Behavioural Inventory (HUDBI). Oral Health Dent Manag. 2013;12(4):255-61.

6. Kateeb E. Gender-specific oral health attitudes and behaviour among dental students in Palestine. Eastern Mediterranean Health Journal. 2010;16(3):329-333.

7. Al Kawas S, Fakhruddin KS, Rehman B. A comparative study of oral health attitudes and behavior between dental and medical students; the impact of dental education in United Arab Emirates. $J$ Int Dent Med Res. 2010;3(1):6-10.

8. Jaramillo JA, Jaramillo F, Kador I, et al. A comparative study of oral health attitudes and behavior using the Hiroshima University-Dental Behavioral Inventory (HU-DBI) between dental and civil engineering students in Colombia. J Oral Sci. 2013;55(1):23-28.

9. Vélez, María Vanessa, Viteri Cevallos MJ, et al. Conocimiento, actitudes y prácticas en salud oral con el Indice Hiroshima University Dental Behavior Inventory hu-dbi en la Facultad de Ciencias Económicas y Administrativas 2015-2016 de la Universidad de Cuenca. Repositorio Digital de la Universidad de Cuenca. 2016:66.

10. Bustos Torres, Yessenia Cristina, Cabrera Toro MM. Conocimiento y prácticas en salud oral con el test de Hiroshima University Dental Behavior Inventory en el Área de Ciencias de la Salud que incluye las carreras de: Medicina, Enfermería, Estimulación Temprana, Fonoaudiología, Imagenología, Terapia Física, Laboratorio Clínico, Nutrición y Dietética, 2016. Repositorio Digital de la Universidad de Cuenca. 2016:46.

11. García Álvarez, Lorena Viviana, Toledo Armijos NP. Prácticas en salud oral con el test de Hiroshima University Dental Behavior Inventory en las facultades de: Jurisprudencia (carreras de: Derecho y Orientación Familiar), Hospitalidad (carreras de, Gastronomía, 
Hotelería y Turismo) y Artes (carreras de: Instrucción Musical, Artes Visuales, Danza y Teatro); de la Universidad de Cuenca, 2015. Repositorio Digital de la Universidad de Cuenca. 2016:72.

12. Parra Solano NF, Saquicela Pulla MG. María Gabriela. Conocimientos, actitudes y prácticas en salud oral con el índice Hiroshima University Dental Behavior Inventory Hu-DBI en el área de Ciencias Técnicas, 2016 de la Universidad de Cuenca. Repositorio Digital de la Universidad de Cuenca. 2016;80.

13. Lafebre Carrasco MF, Diego Cobos Carrera, Carlos Arévalo, et al. Actitudes y conductasde salud oral de estudiantes de Primero a Cuarto Año de Odontología de la Universidad de Cuenca 2014. Acta Odontológica Colombiana. 2015;5(2):47-58.

14. Catarina Fortes, Sónia Mendes, Teresa Albuquerque, et al. Attitudes, behavior and oral health status of 1st year students of Faculdade de Medicina Dentária da Universidade de Lisboa. Sociedade Portuguesa de Estomatologia e Medicina Dentária. 2016.

15. Jaramillo JA, Jaramillo F, Kador I, et al. A comparative study of oral health attitudes and behavior using the Hiroshima University-Dental Behavioral Inventory (HU-DBI) between dental and civil engineering students in Colombia. J Oral Sci. 2013;55(1):23-28.

16. Komabayashi T, Kwan SYL, Hu DY, et al. A comparative study of oral health attitudes and behavior using Hiroshima University- Dental Behavioral Inventory (HU-DBI) between dental students in Britain and China. J Oral Sci. 2005;47(1):1-7.

17. Kawamura M, Honkala E, Widström E, et al. Cross-cultural differences of self-reported oral health behaviour in Japanese and Finnish dental students. Int Dent J. 2000;50(1):46-50.

18. Kawamura M, Honkala E, Widström E, et al. Cross-cultural differences of self-reported oral health behaviour in Japanese and Finnish dental students. Int Dent J. 2000;50(1):46-50.

19. Carrasco FL, Carrera DC, Arévalo C, et al. Actitudes y Conductas de Salud Oral de Estudiantes de Odontología de la Universidad de Cuenca 2014. Acta Odontológica Colomb. 2015;5(2):47-58.

20. Albuquerque T, Bernardo MF, Veiga Simão AM, et al. Reprodutibilidade da Versão Portuguesa Do Hiroshima University Dental Behavioural Inventory (HUDBI - versão portuguesa). Diferenças nas atitudes e comportamentos entre estudantes do $1^{\circ}$ e $3^{\circ}$ ano do curso de Higiene Oral. Rev Port Estomatol Med Dentária E Cirugia Maxilofac. 2011;52(3):125-32.

21. Conferencia Internacional de Educación de las Personas Adultas (CONFITEA). Educación de las personas adultas y los desafios del siglo XXI. Hamburgo: UNESCO; 1999.

22. Dumitrescu AL, Kawamura M, Sasahara H. An assessment of oral self-care among Romanian dental students using the Hiroshima University-Dental Behavioural Inventory. Oral Health Prev Dent. 2007;5(2):95-100.

23. Rojas, Vicente Fuenmayor Fernández. Manual de higiene buccal. Madrid: Panamericana; 2009.

24. van der Weijden F, Slot DE. Oral hygiene in the prevention of periodontal diseases: the evidence. Periodontology 2000. 2011;55 (1):104-123.

25. Reynolds M. Modifiable risk factors in periodontitis: at the intersection of aging and disease. Periodontology 2000. 2013;64(1):7-19.

26. Cowpe J, Plasschaert A, Harzer W, et al. Profile and competences for the graduating European dentist - update 2009: Profile and competences for the European dentist - update 2009. Eur J Dent Educ. 2010;14(4):193-202. 